\title{
Nervous glucose sensing regulates postnatal $\beta$ cell proliferation and glucose homeostasis
}

\author{
David Tarussio, ${ }^{1}$ Salima Metref, ${ }^{1}$ Pascal Seyer, ${ }^{2}$ Lourdes Mounien, ${ }^{3}$ \\ David Vallois, ${ }^{1}$ Christophe Magnan, ${ }^{4}$ Marc Foretz, ${ }^{5}$ and Bernard Thorens ${ }^{1}$

\begin{abstract}
${ }^{1}$ Center for Integrative Genomics, University of Lausanne (UNIL), Lausanne, Switzerland. ${ }^{2}$ Institut de Génomique Fonctionnelle, Montpellier, France. ${ }^{3}$ Laboratoire de Physiologie et Physiopathologie du Système Nerveux Somato-Moteur et Neurovégétatif, Université EA4674 Aix-Marseille — Faculté Saint Jérôme, Marseille, France. ${ }^{4}$ CNRS-University Paris Diderot, Paris, France. 5Institut Cochin — INSERM U1016 — CNRS UMR8104 — Université Paris Descartes, Paris, France.
\end{abstract}

\begin{abstract}
How glucose sensing by the nervous system impacts the regulation of $\beta$ cell mass and function during postnatal development and throughout adulthood is incompletely understood. Here, we studied mice with inactivation of glucose transporter 2 (Glut2) in the nervous system (NG2KO mice). These mice displayed normal energy homeostasis but developed late-onset glucose intolerance due to reduced insulin secretion, which was precipitated by high-fat diet feeding. The $\beta$ cell mass of adult NG2KO mice was reduced compared with that of WT mice due to lower $\beta$ cell proliferation rates in NG2KO mice during the early postnatal period. The difference in proliferation between NG2KO and control islets was abolished by ganglionic blockade or by weaning the mice on a carbohydrate-free diet. In adult NG2 KO mice, first-phase insulin secretion was lost, and these glucose-intolerant mice developed impaired glucagon secretion when fed a high-fat diet. Electrophysiological recordings showed reduced parasympathetic nerve activity in the basal state and no stimulation by glucose. Furthermore, sympathetic activity was also insensitive to glucose. Collectively, our data show that GLUT2dependent control of parasympathetic activity defines a nervous system/endocrine pancreas axis that is critical for $\beta$ cell mass establishment in the postnatal period and for long-term maintenance of $\beta$ cell function.
\end{abstract}

\begin{abstract}
Introduction
Brain nutrient sensing contributes to the control of energy homeostasis by regulating feeding behavior, energy expenditure, and glucose homeostasis (1-3). Part of this regulatory activity is mediated by the autonomic nervous system, which controls not only the metabolic activity of liver, muscle, and fat but also hormone secretion by pancreatic islet endocrine cells. One particular function of the parasympathetic branch of the autonomic nervous system is the stimulation of insulin secretion and of $\beta$ cell proliferation (4). For instance, electrical stimulation of the vagus nerve provokes a glucose-dependent increase in insulin secretion (5-8), and $\beta$ cell proliferation and mass are markedly increased when parasympathetic activity is augmented following lesions of the ventromedial hypothalamus $(9,10)$, whereas bilateral celiac branch-vagus nerve transection reduces $\beta$ cell proliferation by $50 \%$ (11). This nervous activity may also mediate the induction of $\beta$ cell proliferation in response to development of insulin resistance in the liver (12). These effects are mediated by acetylcholine activating $\beta$ cell muscarinic acetylcholine receptor-3 (m3AChR) (13-15), and inactivation of the $m 3 A C h R$ gene in $\beta$ cells reduces insulin secretion and glucose tolerance (16). However, parasympathetic nerve terminals also contain vasoactive intestinal polypeptide (VIP), pituitary adenylate cyclase-activating peptide (PACAP), and gastrin-releasing peptide (GRP) acting as neurotransmitters binding to specific $G$ protein-coupled receptors present on the $\beta$ cell surface (17). Thus, the global parasympathetic control of $\beta$ cells involves activation of $\mathrm{m} 3 \mathrm{AChR}$ and neuropeptide receptors.
\end{abstract}

Conflict of interest: The authors have declared that no conflict of interest exists. Citation for this article: J Clin Invest. 2014;124(1):413-424. doi:10.1172/JCI69154
Preganglionic parasympathetic neurons have their cell bodies in the dorsal motor nucleus of the vagus (DMNX), and those controlling the $\beta$ cells send their terminals to pancreatic ganglions $(18,19)$. The regulation by glucose of the parasympathetic neurons innervating the endocrine pancreas is so far poorly characterized. However, pseudorabies virus retrograde tracing experiments showed these preganglionic neurons to be connected to several brain regions containing glucose-responsive neurons, such as the nucleus of the solitary tract, a brain stem structure adjacent to the DMNX, and different hypothalamic nuclei (20). There is also evidence that glucose interacting with taste buds can activate the vagal nerve to induce the cephalic phase of insulin secretion (21-24), and activation of hepatoportal vein glucose sensors stimulates a vagal reflex that induces first-phase insulin secretion (25-28). The importance of the glucose-regulated parasympathetic innervation in the long-term control of $\beta$ cell mass and function is, however, not established.

In previous studies, we showed that the glucose transporter GLUT2 is required for normal glucose-stimulated insulin secretion and that Glut2-/- mice die around the time of weaning because of impaired insulin secretion (29). The pancreatic islets of these mice had reduced $\beta$ cell number and increased $\alpha / \beta$ cell ratio. We initially postulated that the imbalance between the $\alpha$ and $\beta$ cell populations was caused by impaired insulin secretion reducing autocrine stimulation of $\beta$ cell proliferation and suppressing the negative influence of insulin on $\alpha$ cell proliferation. However, transgenic expression of Glut1 or Glut 2 in the $\beta$ cells of Glut $2^{-}$ mice (ripglut1;glut2-/- or ripglut2;glut2-/- mice), which rescued glucose-stimulated insulin biosynthesis and secretion and allowed survival of the mice, failed to normalize the $\alpha / \beta$ cell ratio (30). This 
A

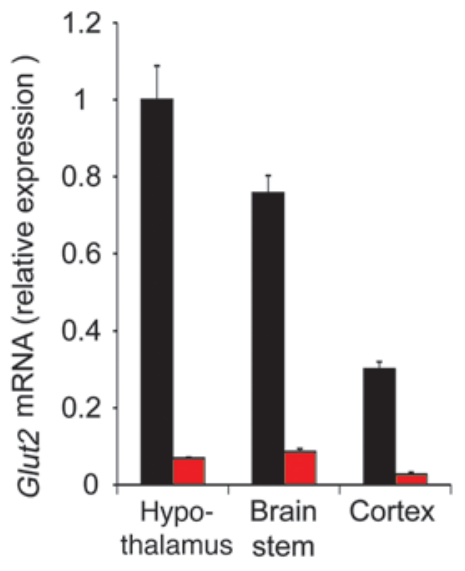

I

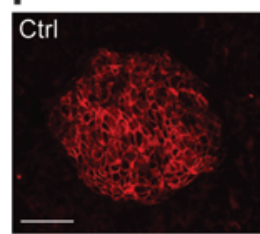

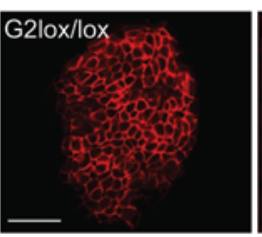
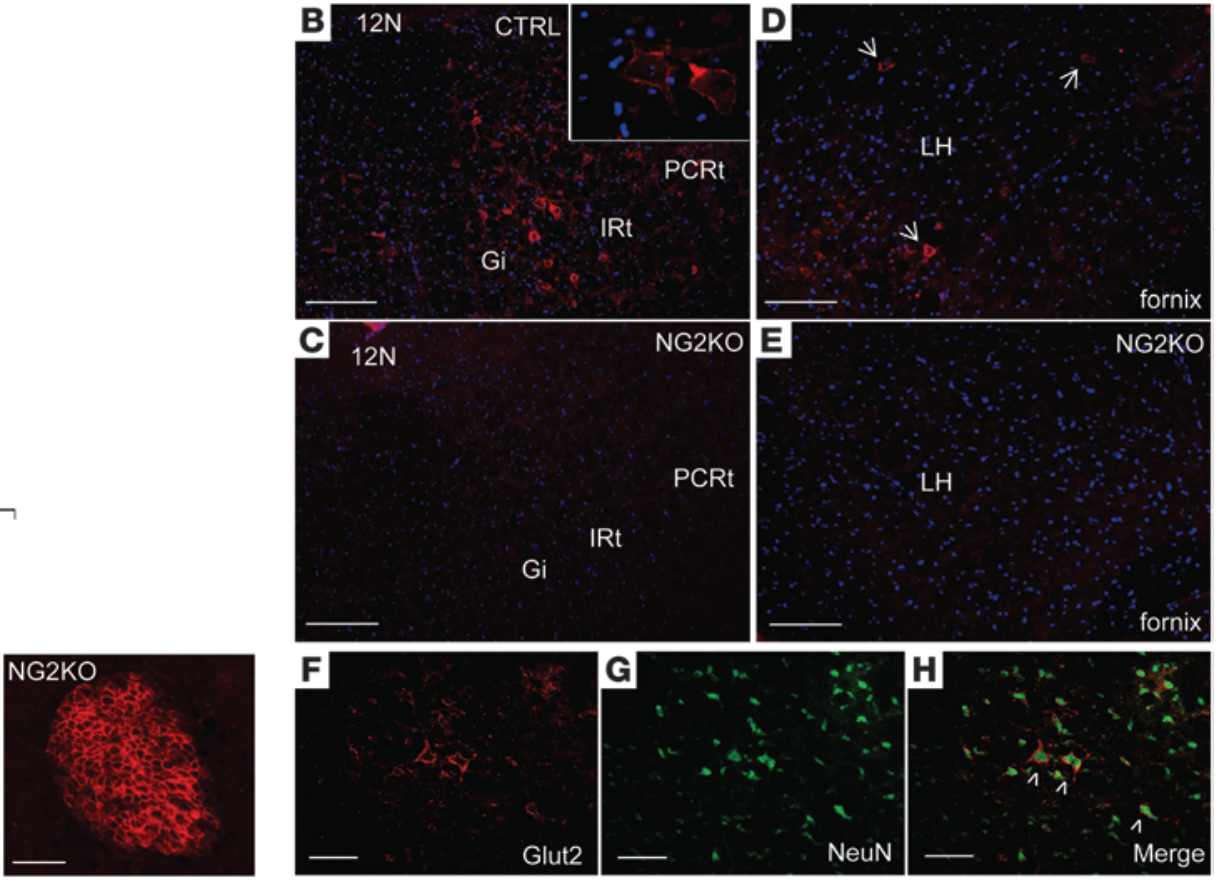

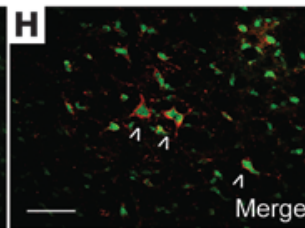

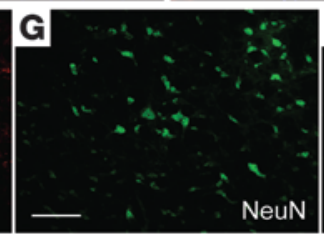

\section{Figure 1}

Glut2 inactivation in the nervous system of NG2KO mice. (A) qRT-PCR analysis of Glut2 expression in the hypothalamus, brain stem, and cortex of control and NG2KO mice. Data are mean \pm SEM; $n=3$. (B and C) Immunofluorescence detection of GLUT2 in the brain stem of control and NG2KO mice. The section were cut at bregma -7.2. Ctrl, control; 12N, hypoglossal nucleus; Gi, gigantocellular reticular nucleus; IRT, intermediate reticular nucleus; PCRt, parvicellular reticular nucleus. Inset: Higher magnification of two neurons showing mostly plasma membrane-associated GLUT2 expression. (D and E) Immunofluorescence detection of GLUT2 in the hypothalamus of control and NG2KO mice. The sections were cut at bregma -1.34. LH, lateral hypothalamus. Arrowheads indicate GLUT2-positive cells. (F-H) Costaining for GLUT2 (red) and NeuN (green) in the brain stem (same region as in B and C) of control mice; arrowheads indicate costained neurons. (I) Immunofluorescence detection of GLUT2 in islets of 24 week-old WT, Glut2lox/lox, and NG2KO mice. Scale bars: $200 \mu \mathrm{m}$ (B and C); $100 \mu \mathrm{m}$ (D-H); $50 \mu \mathrm{m}$ (I).

suggested that the control of $\beta$ cell mass was caused by absence of Glut2 from extra-pancreatic sites. Additional investigations of the ripglut $1 ; g$ lut $2^{--}$mice showed that Glut2 was involved in sensing of glucose in the hepatoportal vein to control glucose absorption by peripheral tissues (31) and first-phase insulin secretion (28), a response that depends on autonomic nervous signaling (27).

In the central nervous system, immunohistochemical studies found GLUT2 expression in relatively rare neurons and astrocytes dispersed in many structures, including the hypothalamus, the brain stem, and the thalamic area (32-35), as well as in tanycytes (36) and some endothelial cells (32). Because the low level of expression of GLUT2 in the brain makes its detection by standard immunocytochemical techniques difficult, we generated mice expressing a fluorescent reporter gene (eYFP) under the control of the GLUT2 promoter (37). Expression of eYFP displayed the same topographical distribution as reported for GLUT2 by immunohistochemical studies, with its typical scattered distribution in many brain structures, including the lateral, paraventricular, and ventrolateral hypothalamus, the zona incerta, and, in brain stem regions including the nucleus of the solitary tract, the dorsal motor nucleus of the vagus nerve, and the basolateral medulla (37), nuclei known to contain glucose-sensitive neurons (2).

Physiological investigation of ripglut $1 ;$ glut2 $2^{--}$mice showed that GLUT2 is involved in central glucose sensing and the control of feeding, thermoregulation, and glucose homeostasis (37-39). However, since the ripglut1;glut $2^{--}$mice are glucosuric
(38) because of a defect in renal glucose reabsorption, they have less demand for insulin secretion, and it was thus not possible to draw direct conclusions about the regulation of $\beta$ cell mass and function by central Glut2-dependent glucose-sensing cells using these mouse models.

Here, we analyzed energy homeostasis and $\beta$ cell mass and function in mice with inactivation of Glut2 in the central and peripheral nervous systems. No difference in body weight, lean and fat mass, energy expenditure, or plasma biochemistry could be observed between control and brain Glut2 knockout mice. However, glucose intolerance developed progressively, a process accelerated by high-fat diet (HFD) feeding. This was associated with reduced $\beta$ cell proliferation in the postnatal period, which led to an approximately 30\% reduction in $\beta$ cell mass in adult mice. Furthermore, we showed that absence of GLUT2 expression in the brain reduced parasympathetic activity both in the basal state and following glucose injection. This defect reduced $\beta$ cell mass, suppressed firstphase insulin secretion, and caused progressive glucose intolerance.

\section{Results}

Glut2 gene inactivation in the nervous system. To generate mice with Glut2 gene inactivation in the nervous system, we crossed Glut2 floxed mice (40) with NesCre mice following a breeding scheme established previously (41). Briefly, male mice carrying one deleted allele of Glut2 and having one copy of the NesCre transgene (Glut2delta+; $\mathrm{Nes} \mathrm{Cre}$ ) were mated with Glut $2^{l o x} / / 0 x$ females to generate mice with 4 different 


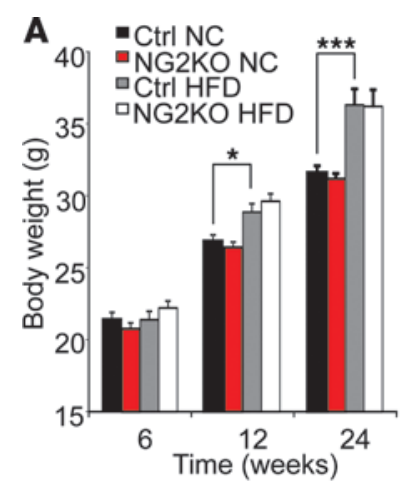

$\mathbf{E}$

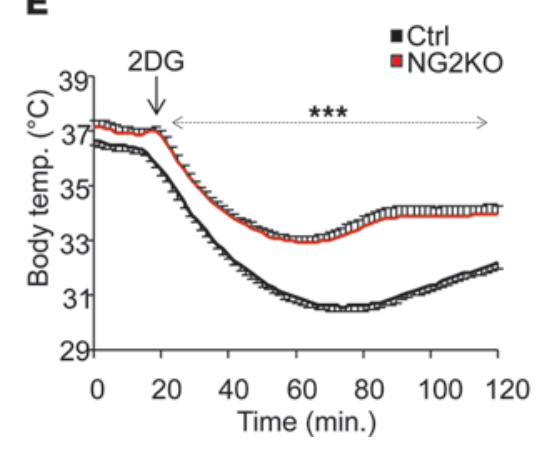

B

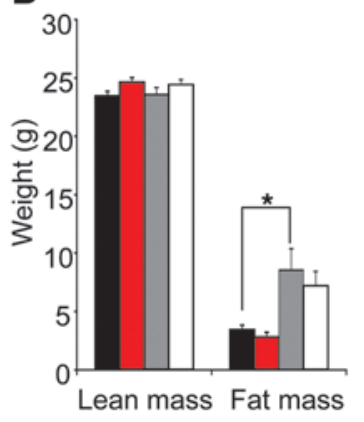

C

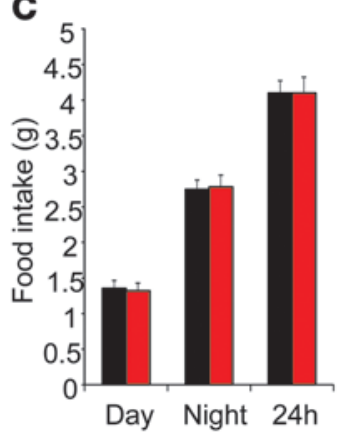

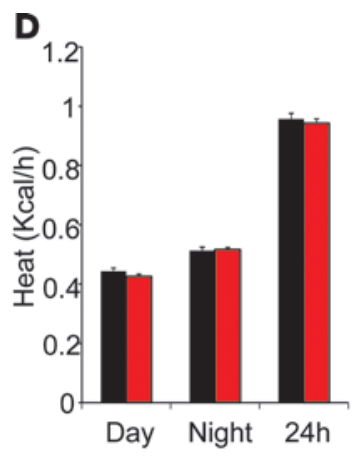

$\mathbf{F}$

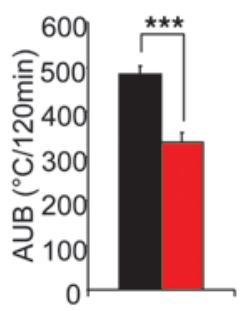

G

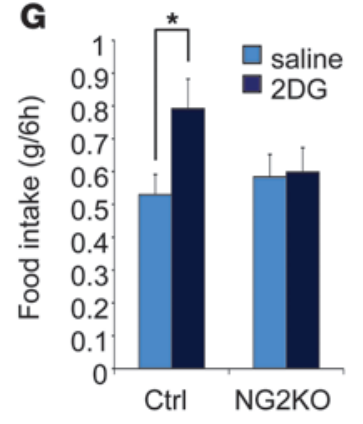

Figure 2

Normal energy homeostasis but impaired response to neuroglucopenia in NG2KO mice. (A) Cohorts of control or NG2KO mice were fed NC or a HFD for the indicated periods of time, and body weights were measured. (B) Lean and fat mass assessed in control and NG2KO mice fed a NC or a HFD for 24 weeks. (C) Food intake assessed in NC-fed control and NG2KO mice. (D) Energy expenditure by control and NG2KO mice fed NC. Data are mean \pm SEM; $n=10-20$. ${ }^{\star} P<0.05 ;{ }^{* * \star} P<0.001$. (E) Online monitoring of body temperature in control and NG2KO mice injected i.c.v. with $1 \mathrm{mg}$ 2-DG at the indicated times. (F) Area under the baseline (AUB) of the hypothermic response to i.c.v. 2-DG. (G) Food intake after i.p. injection of 2-DG in fed control and NG2KO mice. Data are mean \pm SEM; $n=8-16 .{ }^{\star} P<0.05 ;{ }^{* \star \star} P<0.001$.

genotypes: Glut2 delta/lox;NesCre/+ (brainGlut2KO, or NG2KO mice), Glut2+/lox; NesCre/+, Glut2delta/lox;+/+, and Glut2+/lox;+++. Efficient recombination of the Glut2 gene in brain was verified by Southern blot (Supplemental Figure 1A; supplemental material available online with this article; doi:10.1172/JCI69154DS1) and qRT-PCR analysis of GLUT2 expression in hypothalamus, brain stem, and cortex (Figure 1A). Since nestin is expressed in precursors of astrocytes and neurons, the remaining Glut2 mRNA detected by qRT-PCR analysis most probably revealed its expression in other cell types, possibly ependymocytes or endothelial cells $(37,42)$. Immunofluorescence microscopy analysis of brain stem and hypothalamic sections confirmed the absence of GLUT2 expression in the brain of knockout mice (Figure 1, B-E); GLUT2-positive cells detected in the brain stem were mostly neurons, as determined by costaining with the NeuN marker (Figure 1, F-H); GLUT2 was still present in $\beta$ cells (Figure 1I). The nestin-Cre transgene also induces gene deletion in peripheral nervous system and shows mosaic expression in kidney (43). GLUT2 expression in the kidney cortex was, however, identical in control and NG2KO mice (Supplemental Figure 1B). Measurements of urinary glucose excretion showed nonsignificant differences between NG2KO and control mice $(0 \mathrm{mg} / \mathrm{d}$ vs. $2.7 \pm 2.1 \mathrm{mg} / \mathrm{d}$ for control and NG2KO mice, respectively) and unchanged urine volume $(\sim 1.5 \mathrm{ml} / \mathrm{d})$, whereas mice that had no GLUT2 expression in the kidney excreted $>300 \mathrm{mg}$ glucose per day and had daily urinary volume of $>5 \mathrm{ml}$ per day (ref. 38 and Supplemental Figure 1C). Mice of the 4 different genotypes were followed for body weight gain up to 24 weeks, and no difference could be detected between groups; blood glucose levels and food intake were also identical (Supplemental Figure 2, A-C). The absence of any detectable metabolic differences between the three control groups, which expressed one or two alleles of Glut2 in peripheral tissues, is in agreement with our previous studies showing that absence of one allele of Glut2 had no impact on in vivo and in vitro glucose-stimulated insulin secretion $(29,30)$, glucose homeostasis and liver metabolism (44), feeding (45), thermogenesis (37), and glucagon secretion (39) (see also data below). Thus, for the present study we compared Glut2 $2^{\text {delta/lox; }}$ NesCre/+ (NG2KO) with Glut2+/lox; NesCre/+ (control) mice, except where stated otherwise. In all experiments presented here, phenotypic differences were found only when both alleles of Glut2 were deleted from the brain, irrespective of the presence of one or two Glut2 alleles in peripheral tissues.

Normal energy homeostasis but impaired response to central glucopenia in NG2KO mice. Body weights were measured at 6,12 , and 24 weeks of age, and lean and fat mass was assessed at 24 weeks of age. These parameters were indistinguishable in NG2KO and control mice fed either a normal chow (NC) diet or a HFD (Figure 2, A and B). Feeding and energy expenditure during the day and night periods were identical in NG2KO and control mice (Figure 2, C and D). Blood chemistry analysis also revealed no difference between NG2KO and control mice for plasma levels of lipids, cholesterol, lactate, $\beta$-hydroxybutyrate, leptin, or adiponectin (Table 1). Slightly higher HDL plasma concentrations were found, but only in NC-fed NG2KO 

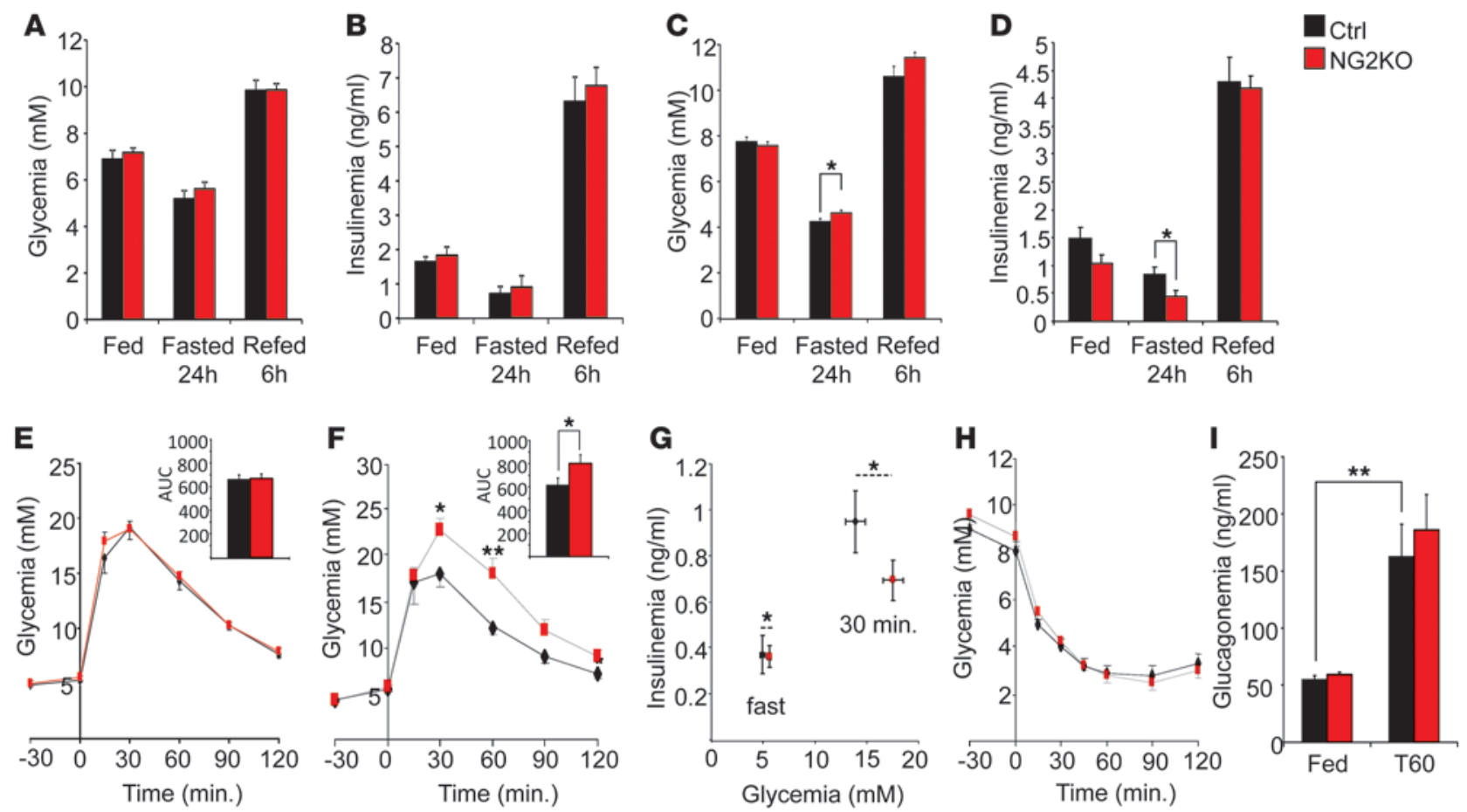

Figure 3

Progressive impairment of glucose tolerance in NG2KO mice caused by defect in insulin secretion. (A) Glycemic levels in 12-week-old control and NG2KO mice in the fed, fasted, and fed and 6-hour-refed states. (B) Plasma insulin levels in the same conditions as A. (C and D) Same measurements as in A and B for 24 week-old mice. (E) Glucose tolerance tests in 12 week-old control and NG2KO mice. (F) Glucose tolerance tests in 24-week-old control and NG2KO mice. (G) Plasma insulin levels in fasted and 30 minutes following an i.p. glucose injection in 24-week-old control and NG2KO mice. (H) Insulin tolerance test in 24-week-old control and NG2KO mice. (I) Glucagon plasma levels in 24-week-old control and NG2KO mice in the fed state and 60 minutes after an i.p. insulin injection $(0.5 \mathrm{U} / \mathrm{kg})$. Data are mean $\pm \mathrm{SEM} ; n=7-16$. ${ }^{\star} P<0.05 ;{ }^{*} P<0.01$.

as compared with control mice; the biological significance of this observation is unclear. These data demonstrate that the presence of one (NG2KO mice) or two (control mice) alleles of Glut2 in peripheral tissues did not impact any of the measured metabolic parameters.

In previous studies, using systemic Glut2-null mice (ripglut1;glut2-/mice), we showed that central GLUT2 was involved in the control of thermoregulation and feeding in response to neuroglucopenia induced by 2 -deoxy-D-glucose $(2-\mathrm{DG})(37,38)$. We thus performed the same experiments with the NG2KO mice. The hypothermic response to i.c.v. injection of $2-\mathrm{DG}$ was markedly reduced in the NG2KO as compared with the control mice (Figure 2, E and F). Similarly, whereas neuroglucopenia stimulated feeding in fed control mice, this was not the case in NG2KO mice (Figure 2G). Thus, specific deletion of Glut2 in the nervous system replicates the phenotypes observed previously in systemic Glut2 knockout mice.

Progressive impairment of glucose homeostasis in NG2KO mice. Next, we assessed glucose homeostasis in 12- and 24-week-old NG2KO and control mice. Figure $3, \mathrm{~A}-\mathrm{D}$, shows the glycemic and insu-

Table 1

Plasma biochemical measurements performed in 24-week-old control and NG2KO fed NC or a HFD

Control

KO

$\begin{array}{lcccc} & \text { NC }(\boldsymbol{n}=\mathbf{8}) & \text { HFD }(\boldsymbol{n}=\mathbf{1 0}) & \text { NC }(\boldsymbol{n}=\mathbf{9}) & \text { HFD }(\boldsymbol{n}=\mathbf{1 0}) \\ \text { Cholesterol }(\mathbf{m M}) & 2.21 \pm 0.19 & 4.92 \pm 0.21 & 2.75 \pm 0.21 & 4.80 \pm 0.15 \\ \text { HDL }(\mathbf{m M}) & 1.84 \pm 0.16 & 3.68 \pm 0.17 & 2.40 \pm 0.18^{\mathrm{A}} & 3.77 \pm 0.11 \\ \text { LDL }(\mathbf{m M}) & 0.11 \pm 0.01 & 0.31 \pm 0.04 & 0.14 \pm 0.02 & 0.36 \pm 0.05 \\ \text { Lactate }(\mathbf{m M}) & 4.66 \pm 0.36 & 4.73 \pm 0.30 & 4.70 \pm 0.14 & 4.69 \pm 0.26 \\ \text { Triglycerides (mM) } & 1.30 \pm 0.16 & 1.91 \pm 0.11 & 1.18 \pm 0.07 & 1.69 \pm 0.12 \\ \text { FFA (mM) } & 0.49 \pm 0.05 & 0.93 \pm 0.05 & 0.59 \pm 0.07 & 0.93 \pm 0.05 \\ \text { HBA (mg/dl) } & 3.31 \pm 0.48 & 5.42 \pm 0.53 & 2.63 \pm 0.22 & 5.11 \pm 0.53 \\ \text { Leptin }(\mathbf{n g} / \mathbf{m l}) & 3.02 \pm 0.39 & 17.65 \pm 3.81 & 2.63 \pm 0.32 & 15.55 \pm 2.74 \\ \text { Adiponectin }(\mu \mathbf{g} / \mathbf{m l}) & 3.96 \pm 0.36 & 4.55 \pm 0.37 & 4.31 \pm 0.36 & 4.49 \pm 0.23\end{array}$

ASignificantly different compared with NC-fed control mice. HBA, $\beta$-hydroxybutyrate. 
A
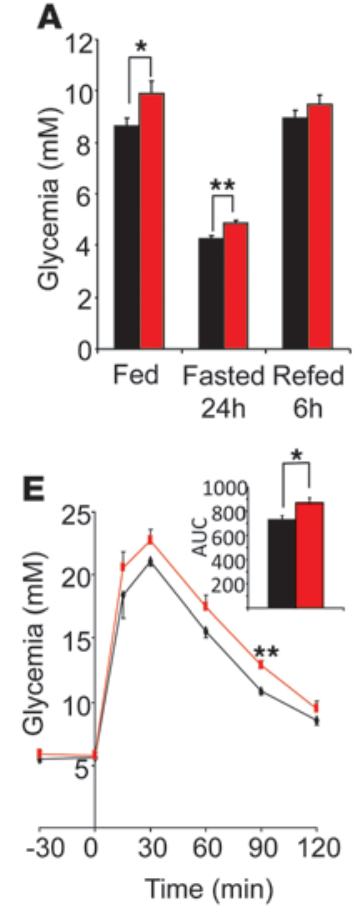

B
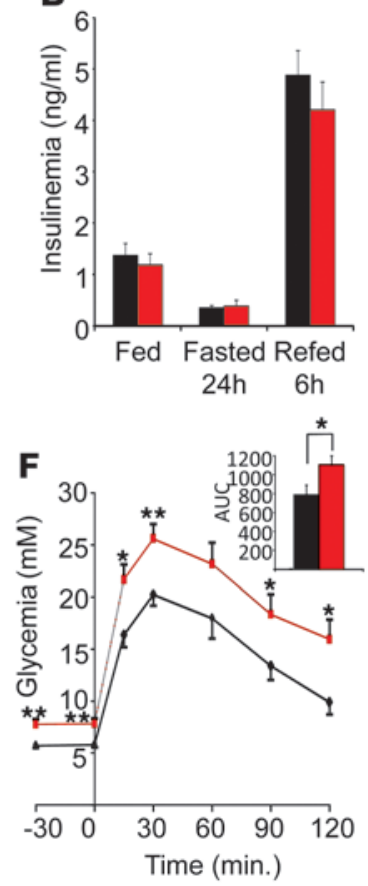
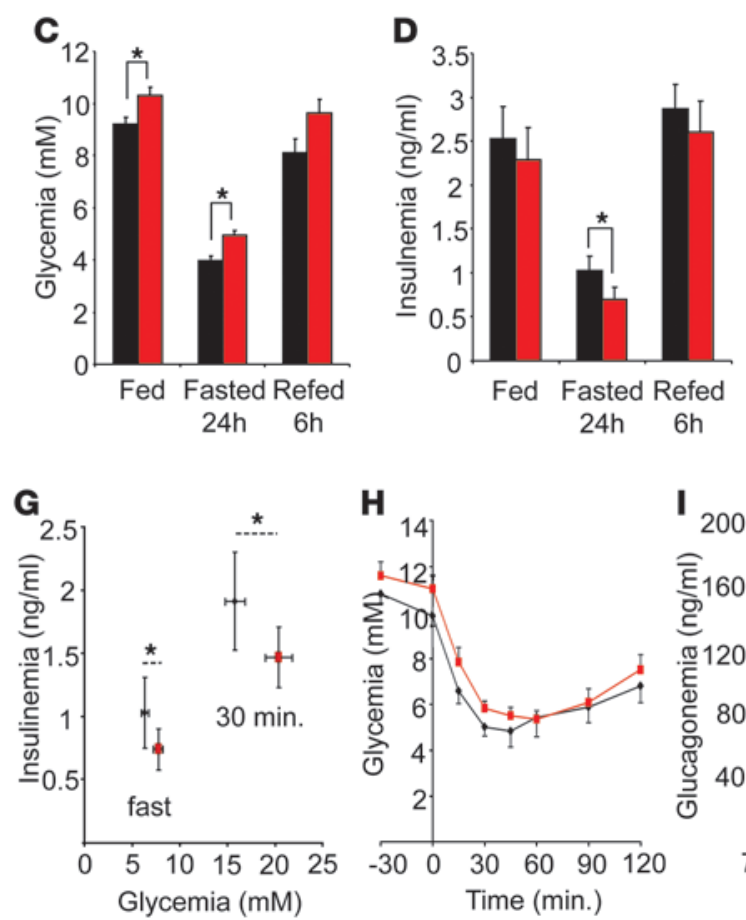

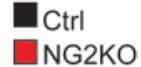

H

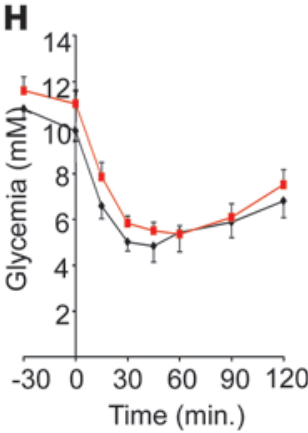

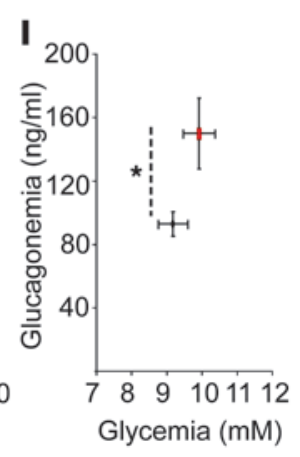

Figure 4

Accelerated development of glucose intolerance in HFD-fed NG2KO mice. (A) Glycemic levels in 12-week-old HFD fed control and NG2KO mice in the fed, fasted, and fed and 6-hour-refed states. (B) Plasma insulin levels in the same conditions as A. (C and D) Same measurements as in A and B for 24-week-old HFD-fed mice. (E) Glucose tolerance tests in 12-week-old HFD-fed control and NG2KO mice. (F) Glucose tolerance tests in 24-week-old HFD fed control and NG2KO mice. (G) Plasma insulin levels in fasted and 30 minutes following an i.p. glucose injection in 24-week-old HFD-fed control and NG2KO mice. (H) Insulin tolerance test in 24-week-old HFD-fed control and NG2KO mice. (I) Glucagon plasma levels in 24-week-old HFD-fed control and NG2KO mice. Data are mean $\pm \mathrm{SEM} ; n=6-12 .{ }^{*} P<0.05 ;{ }^{* *} P<0.01$.

linemic levels in fed, 24-hour-fasted, and 6-hour-refed mice. In 12 -week-old mice no difference in glycemia or in insulinemia could be observed between NG2KO and control mice (Figure 3, A and B). In 24-week-old NG2KO mice a small, significant increase in glycemia was observed in the fasted state and was associated with lower plasma insulin levels (Figure 3, C and D). Glucose tolerance tests were normal in 12-week-old mice but abnormal in 24-week-old NG2KO mice (Figure 3, E and F). This was associated with a defect in glucose-stimulated insulin secretion tested in vivo, but insulin sensitivity was normal (Figure 3, G and H). Fed plasma glucagon levels were similar in control and knockout mice, as were the glucagon levels 60 minutes after an i.p. insulin injection (Figure 3I).

When fed a HFD from 6 weeks of age, NG2KO mice displayed slightly elevated glycemic levels in the fed and fasted states already at 12 weeks of age. In 24-week-old mice the higher glycemic level of the fasted state was also associated with reduced insulinemia (Figure 4, A-D). Glucose intolerance was already significantly higher in HFD-fed NG2KO as compared with control mice at 12 weeks of age, and the difference further increased with age ( 24 weeks) (Figure 4, E and F). This was associated with reduced glucose-stimulated insulin secretion but identical insulin sensitivity (Figure 4, G and H). The fed plasma glucagon levels were significantly higher in HFD-fed NG2KO than control mice despite hyperglycemia (Figure 4I). To show that HFD indeed induced glucose intolerance in both control and NG2KO mice, the glucose tolerance tests of NC- and HFD-fed mice have been plotted on separate graphs for control and NG2KO mice (Supplemental Figure 3, A and B).

Reduced insulin secretion in isolated islets from NG2KO mice and reduced total pancreatic $\beta$ cell mass. To assess the cause of defective glucose-stimulated insulin secretion, we isolated islets from 24-week-old NC- and HFD-fed NG2KO and control mice and assessed insulin secretion in the presence of 2.8 and $16.7 \mathrm{mM}$ glucose. Islets from NC-fed NG2KO mice showed significantly reduced glucose-stimulated insulin secretion as compared with islets from control mice (Figure 5A). The same was observed for islets isolated from HFD-fed NG2KO mice (Figure 5B). In both conditions the islet insulin content was identical in control and NG2KO mice (Figure 5, A and B).

Histomorphometric analysis of mice fed NC showed a timedependent alteration in $\beta$ cell mass. In 1-week-old NG2KO and control mice the $\beta$ cell mass was identical, but it was reduced by approximately $30 \%$ as compared with controls in 6-week-old knockout mice. Although total $\beta$ cell mass continued to increase over time in both control and NG2KO mice, the $\beta$ cell mass remained approximately $30 \%$ lower in 12-and 24-week-old NG2KO as compared with control mice (Figure 6, A-D). In HFD-fed mice, total $\beta$ cell mass was not greater than in NC-fed mice at 12 and 24 weeks of age, and the same relative mass reduction was seen in NG2KO as compared with control mice (Figure 6, I and J). $\alpha$ Cell mass remained identical in the pancreas of NC- or HFD-fed NG2KO and control mice over the entire period of investigation (Figure 6, E-H, K, and L). Analysis of 


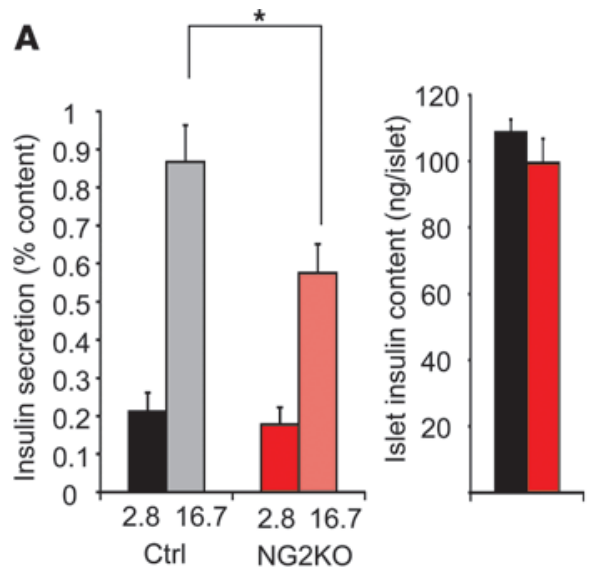

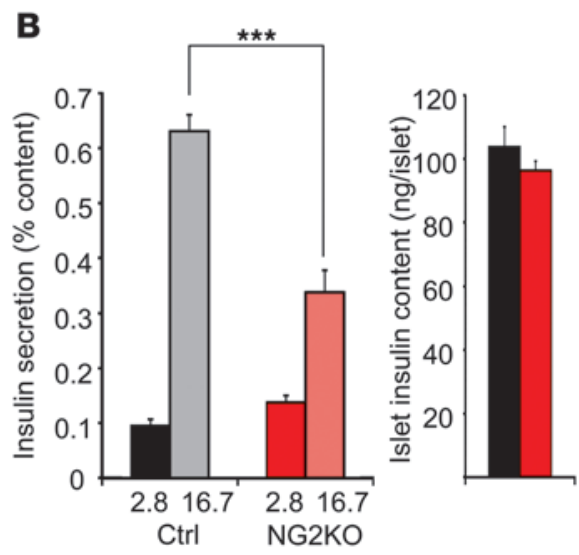

\section{Figure 5}

Glucose-stimulated insulin secretion from isolated pancreatic islets. (A) Left: Islets from 24-week-old NC-fed control and NG2KO mice were incubated for 1 hour in the presence of the indicated glucose concentrations. Right: Insulin content in the islets used in the secretion experiments. (B) As in $\mathbf{A}$ for islets from 24-week-old HFD-fed control and NG2KO mice. Data are mean \pm SEM; $n=4-8$. ${ }^{\star} P<0.05 ;{ }^{\star \star \star} P<0.001$. islet size and number in the pancreas of control and NG2KO mice, determined in 1-, 6-, 12-, and 24-week-old mice fed a NC or a HFD diet from 6 weeks of age showed that islet number was identical in the two types of mice at 1 week of age but reduced by approximately $30 \%$ from 6 weeks of age (Figure 7, A and B), as was total pancreatic insulin content (Figure $7 \mathrm{C}$ ). The size distribution of the islets was, however, the same in the control and NG2KO mice (Figure 7D), as was pancreas weight (Figure $7 \mathrm{E}$ ). Thus, the reduction in $\beta$ cell mass was due to a smaller number of islets per pancreas. The $\alpha / \beta$ cell ratio was increased in the islets of NG2KO mice (Supplemental Table 1), consistent with the fact that $\alpha$ cell mass was not different in NG2KO mouse pancreas (Figure 6, K and L).

Since the difference in $\beta$ cell mass was established between 1 and 6 weeks of age and the relative difference did not change beyond this age, this suggested that the early postnatal period involves a phase of $\beta$ cell mass expansion that may be lacking in NG2KO mice. To test this hypothesis, we measured BrdU incorporation in $\beta$ cells from 14- to 16-day-old mice. BrdU incorporation in $\beta$ cells was indeed much higher in control than in NG2KO mice (Figure 8, $A$ and $B$ ), and this was specific to $\beta$ cells, as no increase in $\alpha$ cell BrdU labeling could be seen at that age (Figure 8C). Importantly, in 6 -week-old mice, there was no difference in $\beta$ cell proliferation between knockout and control mice (Figure 8D). Thus, in NG2KO mice a critical phase of $\beta$ cell expansion was absent in the postnatal period. This suggested that the difference could be due to the switch from suckling to NC feeding, i.e., from a lipid-rich to a carbohydrate-rich diet. To test this hypothesis, we fed control and NG2KO mice a carbohydrate-free HFD starting 5 days before measurement of BrdU incorporation. As shown in Figure $8 \mathrm{E}$, the total $\beta$ cell BrdU incorporation in 2 -week-old mice was much lower than in NC-fed mice, and, importantly, it was no longer different in control and NG2KO mice. This, therefore, showed that postnatal $\beta$ cell proliferation in mice weaned on NC depends on a direct effect of glucose on $\beta$ cells and an indirect effect that requires GLUT2 expression in the nervous system. To exclude the possibility that the difference in $\beta$ cell proliferation at 2 weeks of age, as well as the $\beta$ cell mass in adult mice, was influenced by the expression of one instead of two alleles of Glut 2 in $\beta$ cells, we also measured, in an independent experiment, $\beta$ cell proliferation and mass in NG2KO, Glut $2^{+/ l o x} ; \mathrm{NesCre} /+$ (con-

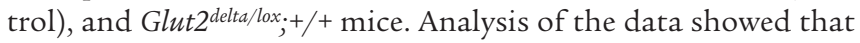
the decrease in $\beta$ cell proliferation and reduced $\beta$ cell mass were not influenced by the presence of one or two alleles of Glut2 in $\beta$ cells, but were caused by complete Glut 2 knockout in the brain (Supplemental Figure 4, A and B).

Impaired parasympathetic activity in NG2KO mice reduces $\beta$ cell proliferation and first-phase insulin secretion. Since parasympathetic nervous activity can control $\beta$ cell proliferation and function (3, 9-11), we tested whether absence of Glut2 in the nervous system could lead to abnormal control of autonomic nervous activity. We directly measured the firing activity of the parasympathetic and sympathetic nerves. Figure 9, A-C, shows that the firing rate of the parasympathetic nerve was lower in NG2KO mice and was not increased following i.p. glucose injection. The firing activity of the sympathetic nerve was the same in both types of mice in the basal state (Figure 9, D-F). However, whereas i.p. glucose reduced firing in the control mice, no such regulation was observed in the NG2KO mice. Thus, NG2KO mice showed suppressed regulation by glucose of both branches of the autonomic nervous system, with, however, a more profound effect on the parasympathetic activity. Measurement of parasympathetic activity in a separate experiment comparing $\mathrm{NG} 2 \mathrm{KO}$, control, and Glut $2^{\text {delta/lox}} ;+/+$ mice showed again that the loss of activation by glucose was entirely dependent on the complete suppression of GLUT2 expression in the nervous system and independent of one or two alleles of Glut2 being expressed in peripheral tissues, although in this experiment there was no significant difference in the basal state between the three genotypes (Supplemental Figure $5 \mathrm{~A}$ ), possibly due to their relatively younger age (14-17 weeks old vs. 25-27 weeks old for the experiments in Figure 9, D-F).

To assess whether impaired control by glucose of the autonomic nervous system impacted $\beta$ cell secretory activity in 8 - to 10 -weekold mice, we measured first-phase insulin secretion following i.p. glucose injection, a response that depends on nervous control of islet cells rather than a direct effect of glucose on $\beta$ cells $(27,28)$. As shown in Figure 9G, 2 minutes after i.p. glucose injection a first peak of insulin secretion was detected in control but not in NG2KO mice. The same insulin plasma levels were seen in both types of mice at 30 minutes, and the glycemic levels were identical at the two time points (Figure 9H). To confirm that this loss of first-phase insulin secretion was not due to a $\beta$ cell defect, we performed perifusion experiments with islets isolated from 8- to 10-week-old mice. Figure 9I shows that the rate of onset of secretion as well as first and second phases of secretion were identical in the two islet types. As this experiment was performed with islets from young mice, this also indicates that the secretory defect observed in 24-week-old mouse islets (Figure 5A) was due to an age-dependent development of impaired insulin secretion. 


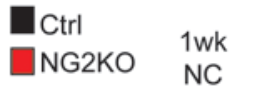

A

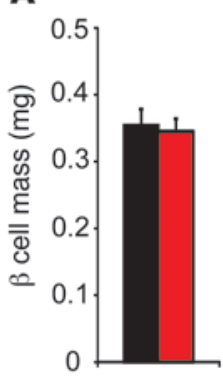

B

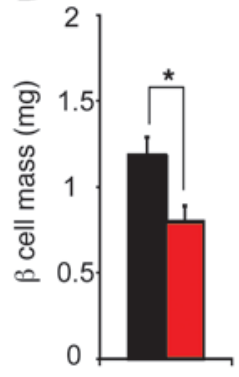

$6 w k$

NC
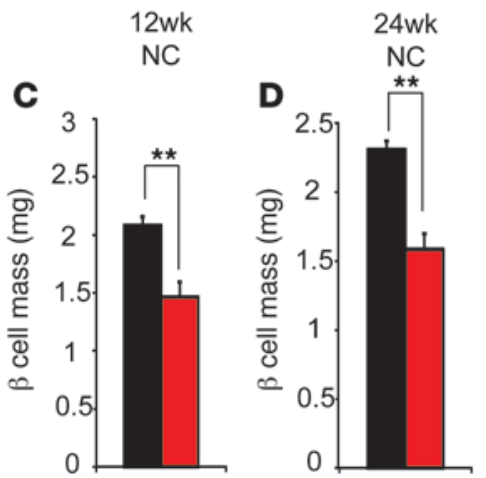

F

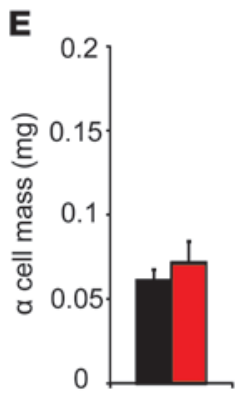

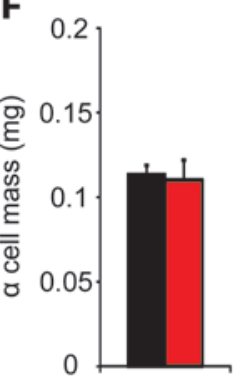

G

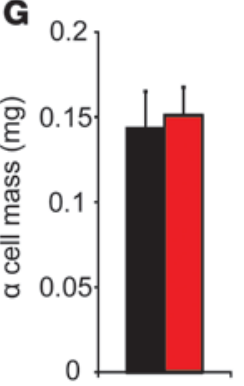

H

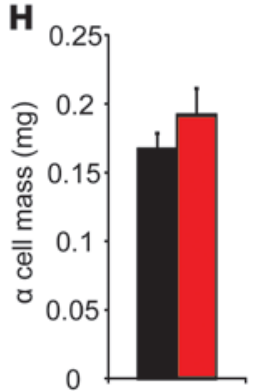

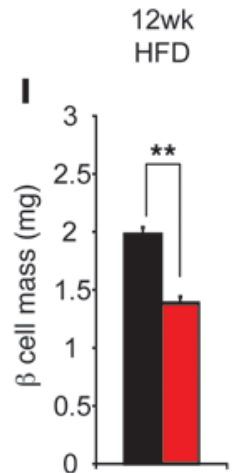

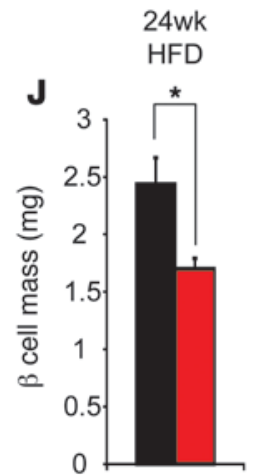

K

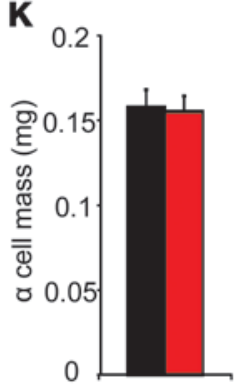

$\mathbf{L}$

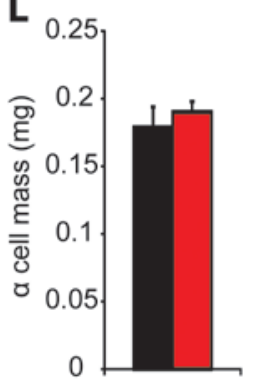

Figure 6

Reduced $\beta$ cell but normal $\alpha$ cell mass in NG2KO mice. (A-D) $\beta$ Cell mass in 1-, 6-, 12-, and 24-week-old NC-fed control and NG2KO mice. (E-H) $\alpha$ Cell mass in the same islets as in A-D. (I and $\mathbf{J}) \beta$ Cell mass in HFD-fed mice at the indicated times. $(\mathbf{K}$ and $\mathbf{L}) \alpha$ Cell mass in the same islets as in I and J. Data are mean $\pm \mathrm{SEM} ; n=4-6 .{ }^{\star} P<0.05 ;{ }^{* \star} P<0.01$.

We next assessed the expression levels of the m3AChR, Pacapr, Vipr, and Grpr mRNAs in islets from adult control and NG2KO mice. No difference in expression of these genes was detected (Supplemental Figure 5, B and C). In addition, immunostaining for vesicular acetylcholine transporter (vAChT; marker of parasympathetic fibers) and tyrosine hydroxylase ( $\mathrm{TH}$; marker of sympathetic fibers) in the pancreas of control and NG2KO mice showed similar pattern of parasympathetic and sympathetic innervation (Supplemental Figures 6 and 7).

Finally, to determine whether the difference in $\beta$ cell proliferation observed in the postnatal period in NG2KO mice weaned on NC was due to a difference in autonomic nervous activity, we injected 14- to 16-day-old mice with the ganglionic blocker chlorisondamine 24 hours before assessing $\beta$ cell proliferation by a 1-hour BrdU pulse labeling. Figure 8B shows that proliferation of $\beta$ cells in control pancreas was reduced by approximately $50 \%$ by chlorisondamine treatment, reaching the level of BrdU incorporation seen in NG2KO $\beta$ cells. This treatment, however, did not modify the proliferation rate of $\beta$ cells from knockout mice. Thus, at this postnatal stage approximately half of the proliferation activity of $\beta$ cells was due to glucose-dependent parasympathetic stimulation.

\section{Discussion}

In the present study, we provide evidence that expression of the glucose transporter GLUT2 in the nervous system is required for the control by glucose of parasympathetic and sympathetic nervous activities. The major impact of autonomic deregulation is a reduction in $\beta$ cell expansion in the early postnatal period, leading to lower $\beta$ cell mass in adult mice. In addition, in adults, these deregulations are associated with absence of the first phase of glucose-stimulated insulin secretion and abnormally elevated secretion of glucagon when the mice are fed a HFD. Together these data indicate that glucose-controlled autonomous nervous activity is required for the establishment of normal $\beta$ cell mass, the long-term preservation of their function, normal glucagon secretion, and maintenance of glucose homeostasis (see Supplemental Figure 8). These observations may explain the link between variants in the human GLUT2 (SLC2A2) gene, fasting hyperglycemia (46), and the risk of developing type 2 diabetes (47).

Genetic inactivation of Glut2 using nestin-Cre mice leads to suppressed expression of the transporter in the central and peripheral nervous systems. In previous studies we provided evidence that central glucose sensing was impaired in ripglut 1;glut2-/- mice, which showed increased ad libitum feeding and loss of stimulated feeding in response to neuroglucopenia induced by i.p. or i.c.v. injection of 2-DG (38). In the present study, feeding and body weight of the NG2KO mice were indistinguishable from those of control mice, even though the knockout mice had also lost the feeding response to 2-DG-induced neuroglucopenia. This suggests that the hyperphagia observed in ripglut1;glut $2^{-/-}$mice must have been driven by the loss of Glut2 from the kidney, which prevented glucose reabsorption, leading to severe loss of glucose in the urine, associated with reduced glycemic levels in the fasted state. In these previous studies we also showed that central GLUT2-expressing cells were involved in the control of thermoregulation, since i.c.v. 2-DG induced a markedly lower hypothermic response in ripglut1;glut2-/- mice than in control mice (37). The same observation was made in the NG2KO mice, further supporting the existence in the brain of 
A

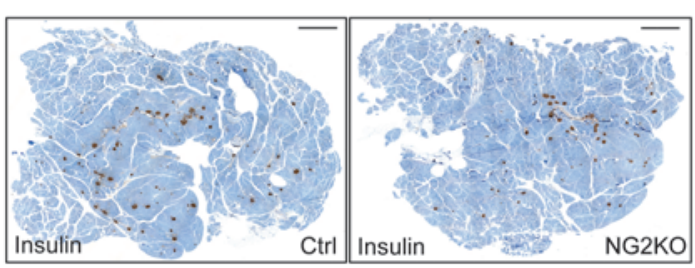

B

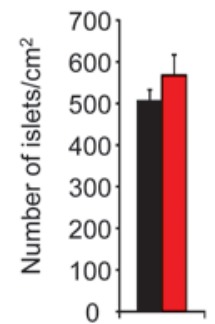

$1 \mathrm{wk}$

NC

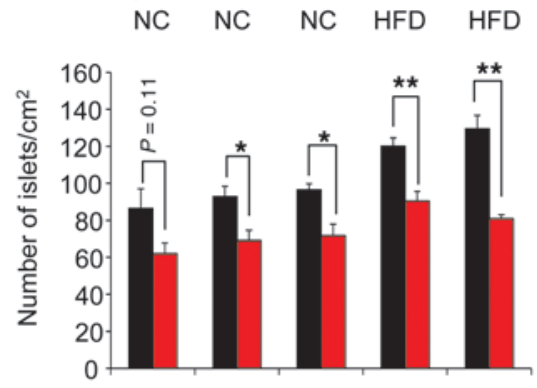

C

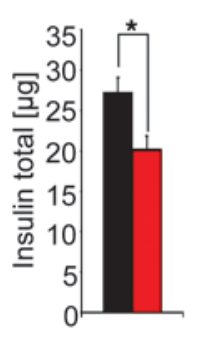

D

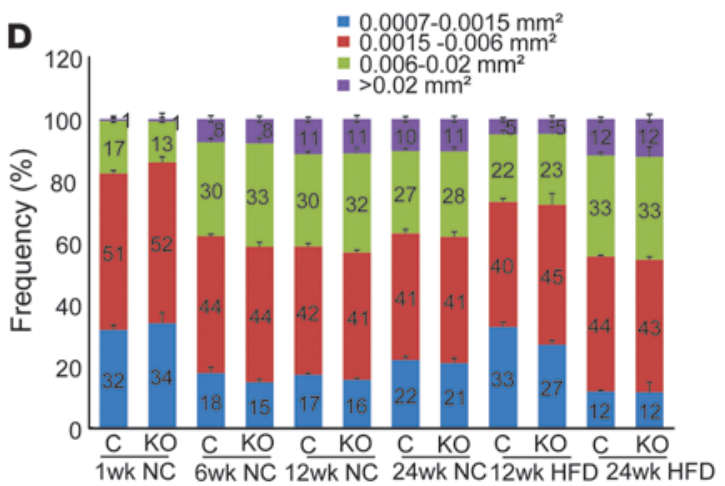

\section{E}

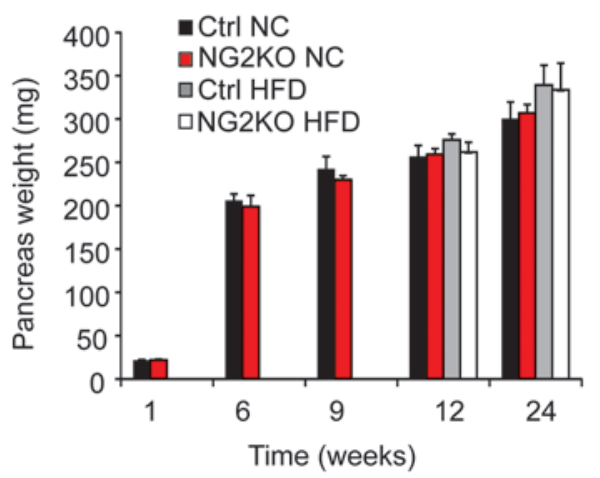

\section{Figure 7}

Reduced islet number but same islet size distribution in control and NG2KO mice. (A) Insulin staining of pancreatic sections from 24-week-old NC-fed control and NG2KO mice. Scale bars: $2 \mathrm{~mm}$. (B) Islet number per pancreas section is reduced in adult NG2KO as compared with control mice. (C) Total pancreatic insulin content in 24-week-old control and NG2KO mice. (D) Islet size distribution in control (C) and NG2KO (KO) mice at the indicated age and fed NC or a HFD. Numbers within the bars indicate the frequency in percentage of the corresponding islet size. (E) Pancreas weight of control and NG2KO mice at the indicated age and fed NC or a HFD. Data are mean \pm SEM; $n=4-6 .{ }^{*} P<0.05 ;{ }^{* *} P<0.01$.

Glut2-expressing cells involved in the control of thermogenesis, possibly by controlling an inhibitory regulation of the sympathetic innervation of brown adipose tissue. Together, the present observations are in agreement with the studies we performed previously with a model of systemic Glut2 gene inactivation. They also demonstrate that the control of feeding and thermoregulation depends on integration of multiple signals in addition to brain glucose sensing, such as the measure of glucose loss in the urine and other sensors of body temperature.

A striking feature of the NG2KO mice was the insensitivity of the sympathetic and parasympathetic nerve activities to glucose, with reduced parasympathetic activity in the basal state and no activation by glucose, whereas sympathetic activity was normal in the basal state but not reduced by glucose.

Parasympathetic nerve activity potentiates glucose-stimulated insulin secretion and can increase $\beta$ cell proliferation $(3,9,10)$. These effects depend on the expression by the $\beta$ cells of m 3 AChR and the receptors for the neuropeptides present in the parasympathetic nerve terminals, PACAP, VIP, and GRP $(3,17)$. Expression of these receptors was normal in the islets of the NG2KO mice. The insensitivity to glucose of the parasympathetic nerve led to two major defects, a reduced $\beta$ cell mass and suppression of the first phase of glucose-stimulated insulin secretion.

The impact on $\beta$ cell proliferation was restricted to the postnatal period, since reduced BrdU incorporation in $\beta$ cells from NG2KO as compared with control mice was observed only in 2-week-old but not in 6 week-old mice, and the difference in the proliferation rate in the younger mice was completely obliterated by ganglionic blockade. That this difference in proliferation was due to glucose present in the food was confirmed when the mice were weaned on a carbohydrate-free diet. This suppressed the difference in proliferation between $\beta$ cells from control and NG2KO mice but also reduced the total BrdU incorporation in $\beta$ cells. This indicates that $\beta$ cell proliferation in the postnatal period requires a direct effect of glucose on $\beta$ cell proliferation and an indirect one, which depends on glucose activating the parasympathetic innervation of $\beta$ cells. Since the differential parasympathetic activity is maintained in adulthood, this also suggests that there is a time window for the parasympathetic activity-induced $\beta$ cell expansion. Although this is not surprising, as other studies have shown that the capacity of $\beta$ cells to proliferate subsides over time $(48,49)$, the reason for this progressive insensitivity is not known.

Importantly, however, absence of this early proliferation phase led to an approximately $30 \%$ reduction in $\beta$ cell mass in 6-weekold mice. This reduced $\beta$ cell mass was due to a reduced number of islets with the same size distribution as in control mice; this is in agreement with a report that the postnatal $\beta$ cell proliferation phase is followed an islet fission phase that reaches its maximum at 3 weeks of age and is responsible for establishing islet size and number in adult mice (50). At 12 and 24 weeks of age the $\beta$ cell mass still expands in both control and NG2KO mice, but the $30 \%$ difference in mass is maintained. This suggests that the lack of the initial phase of expansion cannot be compensated by the subsequent proliferation of $\beta$ cells, which should then depend on mech- 
A

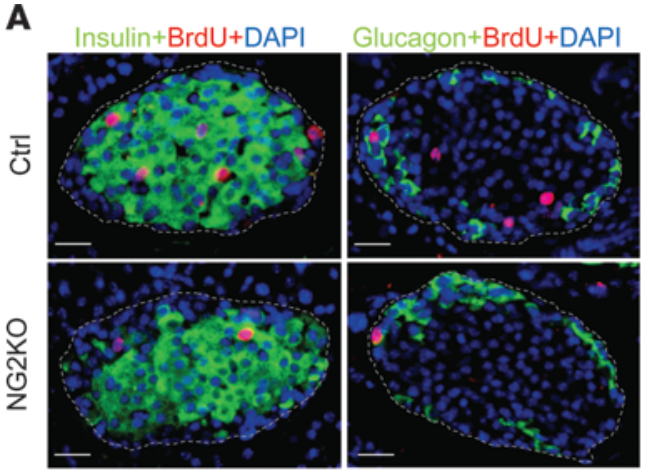

B

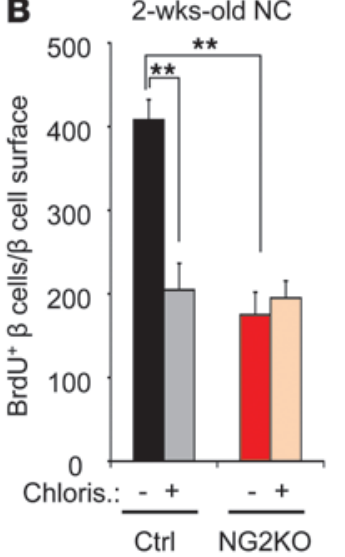

C

2-wks-old NC

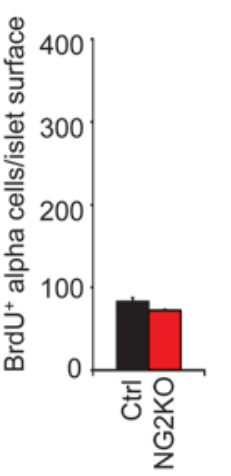

D

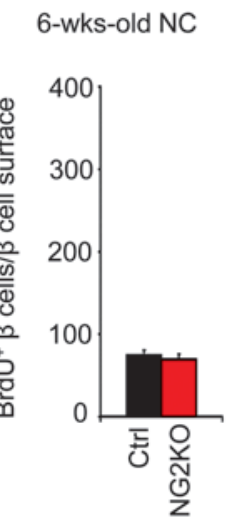

E

2-wks-old HFD

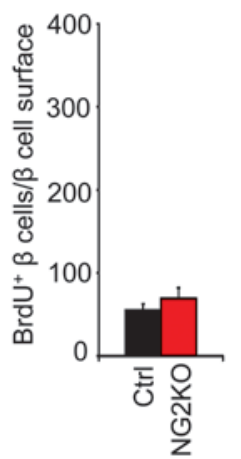

\section{Figure 8}

Reduced $\beta$ cell proliferation in 2-week-old NG2KO mice. (A) Immunostaining of pancreatic sections in 2-week-old control and NG2KO mice for insulin, BrdU, and DAPI; BrdU was injected 1 hour before animals were killed. Scale bars: $50 \mu \mathrm{m}$. (B) Quantitative analysis of BrdU incorporation in $\beta$ cells in control and NG2KO mice. For parasympathetic blockade, chlorisondamine (Chloris.) was injected 23 hours before the BrdU injection. (C) $\alpha$ Cell proliferation in the pancreas of 2-week-old control and NG2KO mice. (D) $\beta$ Cell proliferation in the pancreas of 6-week-old control and NG2KO mice. (E) $\beta$ Cell proliferation in the pancreas of 2-week-old mice fed, together with their mother, a carbohydrate-free diet from day 5 after birth. Data are mean $\pm \mathrm{SEM} ; n=4-5 .{ }^{* \star} P<0.01$.

anisms not under the control of parasympathetic nerve activity. These observations are similar to those made in humans, which showed an intense phase of $\beta$ cell expansion in infancy thought to be critical for the establishment of a basal $\beta$ cell mass, possibly influencing the susceptibility to develop type 2 diabetes $(51,52)$. Our data now indicate a role for glucose and the parasympathetic nervous system in this proliferation phase, indicating a link between early nutrition and establishment of adult $\beta$ cell mass.

The reduction of $\beta$ cell mass is, however, not directly associated with a defect in glucose homeostasis, as glucose intolerance appeared only late in life, well after the difference in $\beta$ cell mass was established. This suggests that reduced $\beta$ cell mass early in life, combined with permanent loss of glucose-stimulated parasympathetic activity, leads to progressive impairment of insulin secretion in vivo, causing glucose intolerance. Here, it is interesting to compare the phenotype of the NG2KO mice with that of mice with $\beta$ cell-specific inactivation of the $m 3 A C h R$ gene. The $m 3 A C h R$ knockout mice (14) are glucose intolerant because of a defect in insulin secretion, but their islet insulin content is normal. In NG2KO mice, the $\beta$ cell mass is reduced, but the defect in glucose-stimulated insulin secretion leads to glucose intolerance only late in life. The absence of reduced $\beta$ cell mass in $m 3 A c C h R$ knockout mice may be explained by the fact that these mice still express the receptors for PACAP, VIP, and GRP, which may maintain normal $\beta$ cell mass but may be insufficient to preserve secretion activity in the absence of cholinergic stimulation. In the NG2KO mice, there is a global reduction in parasympathetic activity, leading to a reduction in both cholinergic and peptidergic signaling, which may explain the more profound effect on $\beta$ cell mass with a lesser impact on insulin secretion. However, because a high-fat/high-carbohydrate diet accelerates development of glucose intolerance in $\mathrm{NG} 2 \mathrm{KO}$ versus control mice without increasing the relative difference in $\beta$ cell mass, this suggests that glucose-induced parasympathetic activity normally plays a protective role against insulin secretion deregulation.

One important yet unresolved question is the identity of the GLUT2-expressing cells that control parasympathetic nervous activity. Because in NG2KO mice Glut2 is inactivated in both neurons and astrocytes, we cannot determine whether GLUT2 expression is required in either or both types of cells for the control of autonomic nervous activity. Retrograde tracing experiments by injection of pseudorabies viruses in the pancreas (20) have shown that the parasympathetic neurons of the dorsal motor nucleus of the vagus that innervate the pancreas are not only connected to neurons of the adjacent nucleus of the solitary tract but also to neurons present in several hypothalamic nuclei such as the lateral hypothalamus, the paraventricular nucleus, or the zona incerta. GLUT2 is expressed in neurons of each of these structures, as determined by immunohistochemical localization (32) and genetic tagging experiments (37). Functional studies also provided evidence that astrocytes express GLUT2 and may also take part in central glucose sensing and glucoregulation (39), in particular in glucagon secretion. Here, we observed normal glucagon secretion in response to insulin-induced hypoglycemia in NC-fed NG2KO mice, but marked hyperglucagonemia in HFD-fed NG2KO mice. This confirms our previous observations with Glut $2^{-/-}$and ripglut1;glut2 $2^{-/-}$mice $(29,53)$ that extrapancreatic GLUT2-expressing cells are involved in the control of glucagon secretion. Determining which GLUT2-expressing cells controls activity of the sympathetic or parasympathetic nerve is the focus of ongoing work.

Thus, collectively our data show that expression of GLUT2 in the nervous system is important for the control by glucose of parasympathetic and sympathetic nervous activities. They provide strong evidence that the glucose-dependent parasympathetic activity is required for $\beta$ cell mass expansion in the postnatal period and for the establishment of the normal $\beta$ cell mass in the adult. Absence of the glucose-dependent parasympathetic activity, probably because of combined defects in the establishment of normal $\beta$ cell mass and lack of adequate $\beta$ cell stimulation in the adult period, progressively leads to insufficient insulin secretion and glucose intolerance. Because a high-fat/high-carbohydrate diet accelerates the development of glucose intolerance in NG2KO as compared with control mice, this suggests that the 

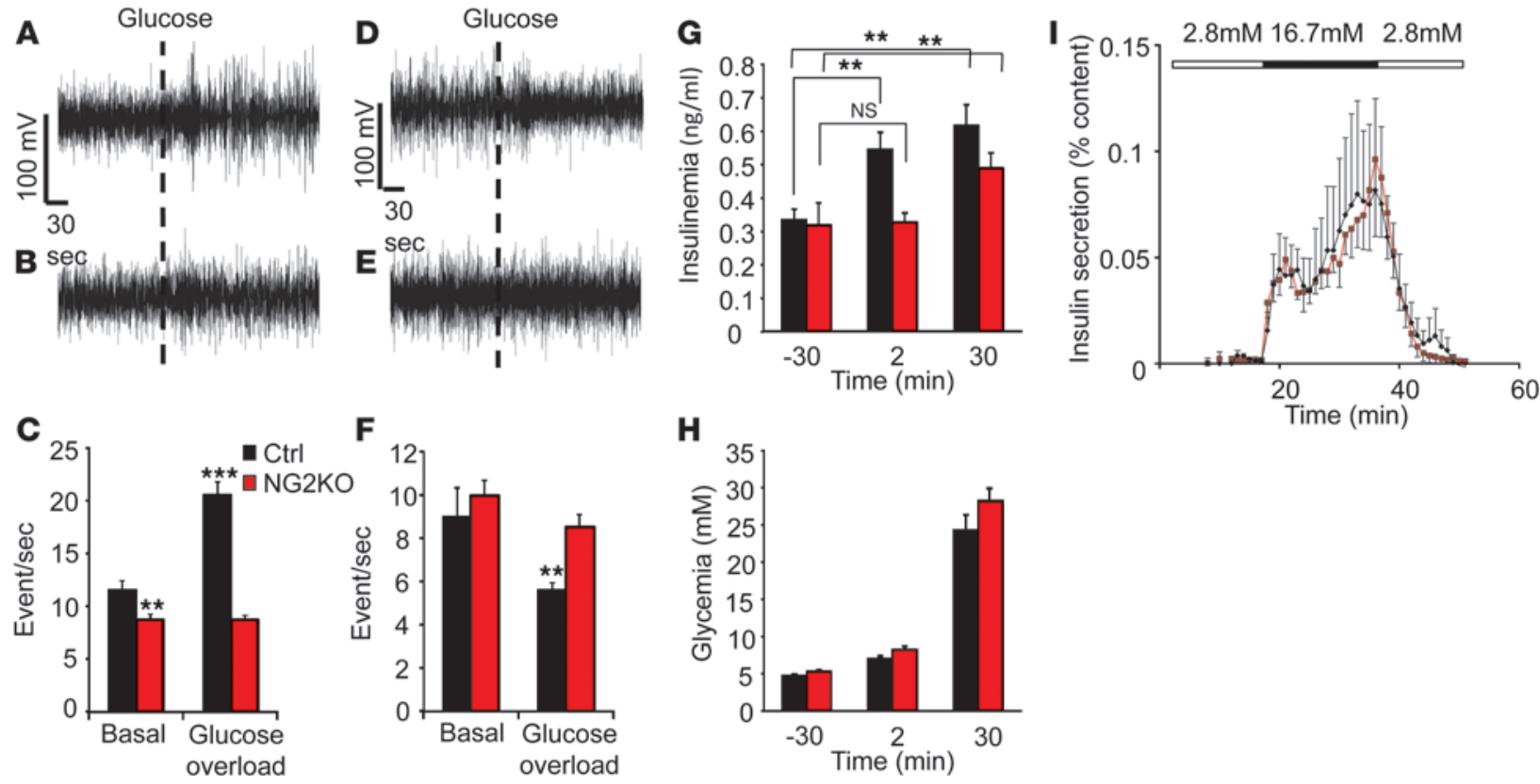

Figure 9

Impaired regulation by glucose of autonomic nervous activity and loss of first-phase insulin secretion in NG2KO mice. (A and B) Recordings of parasympathetic activity in control (A) and NG2KO (B) mice, in the basal state and after i.p. injection of glucose (dotted line). (C) Quantification of firing activity. ( $\mathbf{D}$ and $\mathbf{E})$ Recordings of sympathetic activity in control (D) and NG2KO (E) mice, in the basal state and after i.p. injection of glucose. (F) Quantification of sympathetic firing activity. Data are mean \pm SEM; $n=5 ;{ }^{* \star} P<0.01,{ }^{* \star \star} P<0.001$ versus basal. (G) Plasma insulin levels in 8- to 10-week-old control and NG2KO mice in the fasted state and 2 and 30 minutes after i.p. glucose injection. (H) Blood glucose concentrations at the times of insulin measurements. Data are mean $\pm \mathrm{SEM} ; n=6-9 ;{ }^{* *} P<0.01$. (I) Glucose-stimulated insulin secretion from 8- to 10-week-old control and NG2KO islets. $n=4$ for each perifusion. Data are mean \pm SEM.

parasympathetic activity normally has a protective role against $\beta$ cell dysfunction induced by high-calorie diets. Finally, they show that absence of GLUT2-dependent glucose sensing by the nervous system induces modifications that are characteristic of the progression to type 2 diabetes, reduced $\beta$ cell mass, loss of first-phase insulin secretion, and abnormally elevated glucagon secretion. These defects are furthermore exaggerated by energy-rich diets, establishing nervous glucose sensing as a critical site of gene-environment interaction in the pathogenesis of metabolic diseases. In this context, it is interesting to note that genome-wide association studies have linked variants in the GLUT2 (SLC2A2) gene to fasting hyperglycemia (46) and the risk of developing type 2 diabetes (47). As decrease in GLUT2 expression is unlikely to reduce glucose-stimulated insulin secretion since human $\beta$ cells also express GLUT1 and GLUT3 (54), the present data suggest that the genetic link between Glut2 variants and impaired glycemic control may rather reveal central functions of GLUT2 similar to that reported in the present study.

\section{Methods}

Mice. Mice with Glut2 floxed alleles were as described previously (40). Crossing of Glut $2^{\text {lox }}$ mice with nestin-Cre transgenic mice was performed according to ref. 41 to generate mice with 4 genotypes: Glut2 $2^{\text {delta/lox }} ; \mathrm{NesCre} /+$ (brainGlut2KO, or NG2KO, mice), Glut2+/lox; NesCre/+, Glut2delta/lox; +/+, and $\mathrm{Glut}_{2}+/ \operatorname{lox} ;+++$. Genotyping was performed by Southern blot analysis. All mice studied were littermates; they were on a mixed C57BL/6;SV129 background. Animals were housed on a 12-hour light/dark cycle and were fed a standard rodent chow (Diet 3436, Provimi Kliba AG), a high-fat, high-sucrose diet (Diet 12331, Research Diets), or a carbohydrate-free diet (Ketogenic diet XL75:XP10, Provimi Kliba AG).

Biochemical measurements. Blood glucose levels were measured using a glucometer (Ascensia Breeze 2, Bayer Healthcare). Plasma concentration of total cholesterol, HDL, LDL, $\beta$-hydroxybutyrate, lactate, triglycerides, and free fatty acids were measured with a Hitachi robot (Roche), according to the manufacturer's instructions. Insulin was measured using an ultrasensitive mouse insulin ELISA (Mercodia). For determination of pancreatic insulin or glucagon content, pancreata were quickly dissected, weighed, and homogenized in acid ethanol. Insulin, glucagon, leptin, and adiponectin were measured by RIA (Linco Research). Glycosuria was determined using plastic strips (Keto-Diabur Test 5000, Roche).

Indirect calorimetry, food intake, and body temperature. Indirect calorimetry was performed using an 8-chamber Oxymax system (Columbus Instruments) to measure heat production calculated from oxygen consumption and $\mathrm{CO}_{2}$ production and to measure food intake. Mice were allowed to acclimate to the cages for 2 days before 1 or 2 cycles of 24-hour measurements. Fat mass and lean body mass were determined using an EchoMRI whole body composition analyzer (Echo Medical Systems).

For online temperature monitoring, mice were abdominally implanted with a transponder (G2 E-mitter, Mini-Mitters Inc. or Data Sciences International). After surgery, they were individually housed and allowed to recover for 1 week. Body temperature was recorded every 2 minutes by telemetry using the ER 400 Energizer/Receiver and VitalView data acquisition components (37).

Intracerebroventricular cannula placement and injections, as well as 2-DG i.p. injections, were performed as described previously (39). Before i.p. glucose administration, mice were fasted for 15 hours. 
Glucose and insulin tolerance tests. For glucose tolerance tests, overnight fasted (16 hours) mice were injected i.p. with glucose $(2 \mathrm{~g} / \mathrm{kg})$. Whole blood was drawn from tail tip for glucose measurements. In vivo glucose-stimulated insulin secretion was determined on separate experiments. Blood was sampled 30 minutes before and 30 minutes after glucose injection. For insulin tolerance tests, mice fasted for 5 hours were injected i.p. with insulin $(0.5 \mathrm{U} / \mathrm{kg})$, and glycemia was measured from tail blood taken at the indicated times after injection.

Immunofluorescence microscopy, histomorphometry, and BrdU labeling. For immunofluorescence detection of GLUT2 in the pancreas, the kidney, and the brain, mice were fixed by perfusion with cold $4 \%$ paraformaldehyde in sodium phosphate buffer $(0.1 \mathrm{M}, \mathrm{pH} 7.4)$ containing $10 \mathrm{mM}$ sodium metaperiodate and $37.5 \mathrm{mM}$ L-lysine (32). The organs were dissected and kept for 4 hours in the same paraformaldehyde solution before overnight incubation in $30 \%$ sucrose and frozen at $-80^{\circ} \mathrm{C}$. Twenty-micrometer cryosections were prepared for immunohistochemical detection of GLUT2 as previously described (55), except that for GLUT2 detection in the brain, the sections were incubated in a blocking buffer consisting of $0.1 \mathrm{M}$ phosphate buffer $\mathrm{pH} 7.4$ containing $3 \%$ bovine serum albumin and $0.05 \%$ Tween 20 . Neurons were identified with a mouse monoclonal antibody directed against NeuN (neuronal nuclei, Chemicon MAB377, diluted 1:200) and detected with an Alexa Fluor 488-labeled goat anti-mouse IgG $(\mathrm{H}+\mathrm{L})$ antibody (Invitrogen A11001, diluted 1:200). For histomorphometric analysis, pancreata were fixed with $4 \%$ paraformaldehyde and embedded in paraffin, and 5 - $\mu \mathrm{m}$-thick sections were prepared. For detection of insulin and glucagon, sections were heated in a microwave in a citrate buffer (12 mM, pH 6.0), preincubated in a permeabilization blocking buffer (0.1 M PBS pH 7.4, 2\% bovine serum albumin, $0.1 \%$ Tween 20 ), and incubated overnight at $4{ }^{\circ} \mathrm{C}$ with polyclonal guinea pig anti-insulin (Dako AO564, diluted 1:400) or anti-glucagon (Linco 4031-01F, diluted 1:500) antibodies. Sections were then incubated for 90 minutes with a biotinylated goat antiguinea pig antibody (Vector Laboratories BA-700, diluted 1:750), incubated for 30 minutes with a biotin-avidin complex (Vector Laboratories), stained using DAB (Sigma-Aldrich), and weakly counterstained with Mayer's hematoxylin (Merck HX948000) without differentiation. $\beta$ and $\alpha$ cell masses were calculated by measuring $\beta$ or $\alpha$ cell surface area using ImageJ software (http:// rsbweb.nih.gov/ij/); 5-6 sections per pancreas and 4-6 pancreata were analyzed per experiment, representing a total of 400-500 islets analyzed per conditions. $\beta$ and $\alpha$ cell mass was then calculated based on individual pancreas weight.

For $\beta$ cell proliferation measurements, mice were injected with BrdU (Sigma-Aldrich B5002) at $100 \mu \mathrm{g} / \mathrm{g}$ body weight 1 hour before sacrifice. Pancreata and sections were prepared as described above. Sections were incubated overnight at $4^{\circ} \mathrm{C}$ with a rat anti-BrdU (Abcam ab6326, diluted $1: 100$ ) and with polyclonal guinea pig anti-insulin (Dako AO564, diluted 1:400) or anti-glucagon (Linco 4031-01F, diluted 1:500) antibodies, then incubated for 90 minutes with Alexa Fluor 568 goat anti-rat IgG $(\mathrm{H}+\mathrm{L})$ (Invitrogen A11077, diluted 1:200) and Alexa Fluor 488 goat anti-guinea pig IgG (H+L) (Invitrogen A11073, diluted 1:200), mounted with Vectashield with DAPI to counterstain nucleus (Vector Laboratories H-1200). Sections were observed using an Axio Imager D1 (Zeiss) microscope interfaced with Axiovision software (Zeiss). BrdU-positive cells costained with insulin or glucagon were counted in $>100$ islets using the ImageJ analysis system. When used, chlorisondamine (Sigma-Aldrich C5366) was injected at $5 \mathrm{mg} / \mathrm{kg} 24$ hours before BrdU treatment.

Islet isolation and insulin secretion analysis. For insulin secretion experiments, islets were isolated by hand-picking after collagenase digestion of pancreata and kept overnight in culture, and insulin secretion following 2-hour incubation in the presence of 2.8 or $20 \mathrm{mM}$ glucose was assessed using batches of 20 islets, as described previously (28). At the end of each static incubation or perifusion, islets were collected and lysed in acid ethanol $(75 \% \mathrm{EtOH} ; 0.55 \% \mathrm{HCl})$ for assessment of insulin content.
Parasympathetic and sympathetic firing-rate recordings. Firing rate activities were recorded at the level of the thoracic branch of the vagus nerve (parasympathetic) and the sympathetic trunk, along the carotid artery in 5-hour-fasted mice, as previously described (56). Different mice were used for recording each activity. Recordings were done as follows: mice were anesthetized with isoflurane (Sanofi). Either parasympathetic or sympathetic nerves, which are close to the carotid artery, were dissected free of underlying tissues on a distance of approximately $5 \mathrm{~mm}$. Nerves were then covered with paraffin oil to prevent dehydration and carefully placed on a pair of recording silver wire electrodes $(0.6-\mathrm{mm}$ diameter). Electrodes were connected to a high-impedance probe, and action potentials were displayed and saved on a computer after initial amplification through a low-noise amplifier (Bio Amp, ADInstruments). Unipolar nerve activity was recorded continuously during $15 \mathrm{~min}$ utes (baseline) and then 15 minutes after a single injection of glucose (ip, $3 \mathrm{~g} / \mathrm{kg}$ ). Data were digitized with digitizer PowerLab/4sp. Signals were amplified $10^{5}$ and filtered at low- and high-frequency cut-offs of 100 and $1,000 \mathrm{~Hz}$ and monitored the with the computer program Chart 4 (ADInstruments) (57).

$R N A$ preparations and quantitative $R T-P C R$. Tissue preparation, RNA extraction, RT-PCR, and quantitative RT-PCR analyses were performed as described previously (37). The following forward (F) and reverse (R) primers were used for qRT-PCR: F5'-TGGGGAACTTAGCCTGTGAC-3' and R5'-GCTGATCACCAGCAGATTCA-3' for $m 3 A C h R$; F5'-ATCTTGTA TGCCGAGCAGGA-3' and R5'-GGACACCACGCAGTAGTGAA-3' for PACAPR; F5'-CCCCCTCATCTTTCAACTGT-3' and R5'CCAGTTGTGACCAGCCTTCT-3' for vasoactive intestinal peptide receptor (Vipr); F5'-TCCCGTGGAAGGCAATATAC-3' and R5'-GAGGCCCACAAACACCAGTA-3' for Grpr; F5'AAGAATAAGGCCCGAGTGGT-3' and R5'-ACCAGTGCAT CTGGATAGGC-3' for $\beta 2$ adrenergic receptor $(\beta 2 A R)$; F5' CCAGTACATTGCGGACTTCCTT- $3^{\prime}$ and R5'-CTTTCCTTTGGTTT CTGGAACTTT-3' for Glut2; F5'-CCTCCAAGGAGTAAGAAACCC-3' and R5'-GGGTGCAGCGAACTTTATTG-3' for Gapdh used as a reference in the islets; F5-GTGATGGAGGAGCTGGTTCG-3' and R5'AGCAGAGGAAGGCTCATTGG-3' for $\beta$-glucuronidase (Gusb) used as a reference in the brain.

Statistics. Data are expressed as mean \pm SD or SEM. Statistical analysis was performed by an unpaired 2 -tailed Student's $t$ test. $P$ values less than 0.05 were considered significant.

Study approval. All breeding and cohort maintenance performed in the UNIL animal facility, and all experiments were approved by the Service Vétérinaire du Canton de Vaud.

\section{Acknowledgments}

This study was supported by grants from the Swiss National Science Foundation (31003A-113525 and 3100A0B-128657), NCCR Frontiers in Genetics, a European Research Council advanced grant (INSIGHT), and the European Union Framework Program 7 Collaborative Project BetaBat. We thank Frédéric Preitner and the mouse Metabolic Facility of the UNIL for help with metabolic measurements.

Received for publication February 13, 2013, and accepted in revised form October 11, 2013.

Address correspondence to: Bernard Thorens, Center for Integrative Genomics, University of Lausanne, Genopode Building, CH-1015 Lausanne, Switzerland. Phone: 41.21.692.3981; Fax: 41.21.692.3985; E-mail: Bernard.Thorens@unil.ch. 
1. Mobbs CV, et al. Impaired glucose signaling as a cause of obesity and the metabolic syndrome: the glucoadipostatic hypothesis. Physiol Behav. 2004; 19(1):2-23.

2. Marty N, Dallaporta M, Thorens B. Brain glucose sensing, counterregulation, and energy homeostasis. Physiology (Bethesda). 2007;22:241-251.

3. Thorens B. Brain glucose sensing and neural regulation of insulin and glucagon secretion. Diabetes Obes Metab. 2011;13(suppl 1):82-88.

4. Thorens B. Central control of glucose homeostasis: the brain--endocrine pancreas axis. Diabetes Metab. 2010;36(suppl 3):S45-S49.

5. Kaneto A, Kajinuma H, Kosaka K. Effect of splanchnic nerve stimulation on glucagon and insulin output in the dog. Endocrinology. 1975;96(1):143-150.

6. Berthoud HR, Bereiter DA, Jeanrenaud B. Role of the autonomic nervous system in the mediation of LHA electrical stimulation-induced effects on insulinemia and glycemia. J Auton Nerv Syst. 1980; 2(2):183-198.

7. Lundquist I. Cholinergic muscarinic effects on insulin release in mice. Pharmacology. 1982; 25(6):338-347.

8. N'Guyen JM, et al. Involvement of the autonomic nervous system in the in vivo memory to glucose of pancreatic beta cell in rats. J Clin Invest. 1994; 94(4):1456-1462.

9. Kiba T. Relationships between the autonomic nervous system and the pancreas including regulation of regeneration and apoptosis: recent developments. Pancreas. 2004;29(2):e51-e58

10. Kiba T, Tanaka K, Numata K, Hoshino M, Misugi $\mathrm{K}$, Inoue S. Ventromedial hypothalamic lesioninduced vagal hyperactivity stimulates rat pancreatic cell proliferation. Gastroenterology. 1996; 110(3):885-893.

11. Lausier J, et al. Vagal control of pancreatic $\beta$-cell proliferation. Am J Physiol Endocrinol Metab. 2010; 299(5):E786-E793

12. Imai J, et al. Regulation of pancreatic $\beta$ cell mass by neuronal signals from the liver. Science. 2008; 322(5905):1250-1254.

13. Gautam D, et al. Beneficial metabolic effects caused by persistent activation of $\beta$-cell M3 muscarinic acetylcholine receptors in transgenic mice. Endocrinology. 2010;151(11):5185-5194.

14. Gautam D, et al. A critical role for $\beta$ cell M3 muscarinic acetylcholine receptors in regulating insulin release and blood glucose homeostasis in vivo. Cell Metab. 2006;3(6):449-461.

15. Henquin JC, Nenquin M. The muscarinic receptor subtype in mouse pancreatic B-cells. FEBS Lett. 1988 236(1):89-92.

16. Gautam D, et al. Role of the M3 muscarinic acetylcholine receptor in beta-cell function and glucose homeostasis. Diabetes Obes Metab. 2007; 9(suppl 2):158-169.

17. Ahren B. Autonomic regulation of islet hormone secretion - implications for health and disease. Diabetologia. 2000;43(4):393-410.

18. Ionescu E, Rohner-Jeanrenaud F, Berthoud HR, Jeanrenaud B. Increases in plasma insulin levels in response to electrical stimulation of the dorsal motor nucleus of the vagus nerve. Endocrinology. 1983;112(3):904-910.

19. Jansen AS, Nguyen XV, Karpitskiy V, Mettenleiter TC, Loewy AD. Central command neurons of the sympathetic nervous system: basis of the fight-orflight response. Science. 1995;270(5236):644-646.

20. Buijs RM, Chun SJ, Niijima A, Romijn HJ, Nagai K. Parasympathetic and sympathetic control of the pancreas: a role for the suprachiasmatic nucleus and other hypothalamic centers that are involved in the regulation of food intake. J Comp Neurol. 2001; 431(4):405-423.
21. Berthoud HR, Trimble ER, Siegel EG, Bereiter DA, Jeanrenaud B. Cephalic-phase insulin secretion in normal and pancreatic islet-transplanted rats. Am J Physiol. 1980;238(4):E336-E340.

22. Berthoud HR, Bereiter DA, Trimble ER, Siegel EG, Jeanrenaud B. Cephalic phase, reflex insulin secretion. Neuroanatomical and physiological characterization. Diabetologia. 1981;20(suppl):393-401.

23. Berthoud HR, Jeanrenaud B. Sham feedinginduced cephalic phase insulin release in the rat. Am J Physiol. 1982;242(4):E280-E285.

24. Berthoud HR, Powley TL. Identification of vagal preganglionics that mediate cephalic phase insulin response. Am J Physiol. 1990; 258(2 pt 2):R523-R530.

25. Niijima A. Glucose-sensitive afferent nerve fibres in the hepatic branch of the vagus nerve in the guinea-pig. J Physiol. 1982;332:315-323.

26. Niijima A. The effect of D-glucose on the firing rate of glucose-sensitive vagal afferents in the liver in comparison with the effect of 2-deoxy-D-glucose. J Auton Nerv Syst. 1984;10(3-4):279-285.

27. Balkan B, Li X. Portal GLP-1 administration in rats augments the insulin response to glucose via neuronal mechanisms. Am J Physiol. 2000; 279(4):R1449-R1454.

28. Preitner F, et al. Gluco-incretins control insulin secretion at multiple levels as revealed in mice lacking GLP-1 and GIP receptors. J Clin Invest. 2004; 113(4):635-645.

29. Guillam M-T, et al. Early diabetes and abnormal postnatal pancreatic islet development in mice lacking GLUT2. Nat Genet. 1997;17(3):327-330.

30. Thorens B, Guillam MT, Beermann F, Burcelin R, Jaquet $M$. Transgenic reexpression of GLUT1 or GLUT2 in pancreatic beta cells rescues GLUT2null mice from early death and restores normal glucose-stimulated insulin secretion. J Biol Chem. 2000 275(31):23751-23758

31. Burcelin R, Dolci W, Thorens B. Glucose sensing by the hepatoportal sensor is GLUT2-dependent. In vivo analysis in GLUT2-null mice. Diabetes. 2000; 49(10):1643-1648.

32. Arluison M, Quignon M, Nguyen P, Thorens B, Leloup C, Penicaud L. Distribution and anatomical localization of the glucose transporter 2 (GLUT2) in the adult rat brain - an immunohistochemical study. J Chem Neuroanat. 2004;28(3):117-136.

33. Arluison M, Quignon M, Thorens B, Leloup C, Penicaud L. Immunocytochemical localization of the glucose transporter 2 (GLUT2) in the adult rat brain. II. Electron microscopic study. J Chem Neuroanat. 2004;28(3):137-146

34. Maekawa F, et al. Localization of glucokinase-like immunoreactivity in the rat lower brain stem: for possible location of brain glucose-sensing mechanisms. Endocrinology. 2000;141(1):375-384.

35. Young JK, McKenzie JC. GLUT2 immunoreactivity in Gomori-positive astrocytes of the hypothalamus. J Histochem Cytochem. 2004;52(11):1519-1524.

36. Garcia Mde L, et al. Hypothalamic ependymal-glial cells express the glucose transporter GLUT2, a protein involved in glucose sensing. J Neurochem. 2003; 86(3):709-724.

37. Mounien L, et al. Glut2-dependent glucose-sensing controls thermoregulation by enhancing the leptin sensitivity of NPY and POMC neurons. FASEB J. 2010;24(6):1747-1758.

38. Bady I, et al. Evidence from glut2-null mice that glucose is a critical physiological regulator of feeding. Diabetes. 2006;55(4):988-995.

39. Marty N, et al. Regulation of glucagon secretion by glucose transporter type 2 (glut2) and astrocytedependent glucose sensors. J Clin Invest. 2005; 115(12):3545-3553

40. Seyer $\mathrm{P}$, et al. Hepatic glucose sensing is required to preserve beta cell glucose competence. J Clin Invest. 2013;123(4):1662-1676.

41. Trumpp A, Depew MJ, Rubenstein JL, Bishop JM, Martin GR. Cre-mediated gene inactivation demonstrates that FGF8 is required for cell survival and patterning of the first branchial arch. Genes Dev. 1999;13(23):3136-3148.

42. Ngarmukos C, Baur EL, Kumagai AK. Co-localization of GLUT1 and GLUT4 in the blood-brain barrier of the rat ventromedial hypothalamus. Brain Research. 2001;900(1):1-8.

43. Dubois NC, Hofmann D, Kaloulis K, Bishop JM, Trumpp A. Nestin-Cre transgenic mouse line Nes-Cre 1 mediates highly efficient Cre/loxP mediated recombination in the nervous system, kidney, and somite-derived tissues. Genesis. 2006; 44(8):355-360.

44. Burcelin R, del Carmen Munoz M, Guillam MT, Thorens B. Liver hyperplasia and paradoxical regulation of glycogen metabolism and glucose-sensitive gene expression in GLUT2-null hepatocytes. Further evidence for the existence of a membranebased glucose release pathway. J Biol Chem. 2000; 275(15):10930-10936

45. Marty N, Bady I, Thorens B. Distinct classes of central GLUT2-Dependent sensors control counterregulation and feeding. Diabetes. 2006; 55(suppl 2):S108-S113.

46. Dupuis J, et al. New genetic loci implicated in fasting glucose homeostasis and their impact on type 2 diabetes risk. Nat Genet. 2010;42(2):105-116.

47. Kilpelainen TO, et al. Physical activity modifies the effect of SNPs in the SLC2A2 (GLUT2) and ABCC8 (SUR1) genes on the risk of developing type 2 diabetes. Physiol Genomics. 2007;31(2):264-272.

48. Tschen SI, Dhawan S, Gurlo T, Bhushan A. Agedependent decline in $\beta$-cell proliferation restricts the capacity of $\beta$-cell regeneration in mice. Diabetes. 2009;58(6):1312-1320.

49. Rankin MM, Kushner JA. Adaptive $\beta$-cell proliferation is severely restricted with advanced age. Diabetes. 2009;58(6):1365-1372

50. Jo J, Kilimnik G, Kim A, Guo C, Periwal V, Hara $\mathrm{M}$. Formation of pancreatic islets involves coordinated expansion of small islets and fission of large interconnected islet-like structures. Biophys J. 2011; 101(3):565-574.

51. Gregg BE, et al. Formation of a human $\beta$-cell population within pancreatic islets is set early in life. J Clin Endocrinol Metab. 2012;97(9):3197-3206.

52. Meier JJ, et al. $\beta$-Cell replication is the primary mechanism subserving the postnatal expansion of $\beta$-cell mass in humans. Diabetes. 2008; 57(6):1584-1594

53. Burcelin R, Thorens B. Evidence that extrapancreatic GLUT2-dependent glucose sensors control glucagon secretion. Diabetes. 2001; 50(6):1282-1289.

54. De Vos A, et al. Human and rat $\beta$ cells differ in glucose transporter but not in glucokinase gene expression. J Clin Invest. 1995;96(5):2489-2495.

55. Thorens B, Sarkar HK, Kaback HR, Lodish HF. Cloning and functional expression in bacteria of a novel glucose transporter present in liver, intestine, kidney, and b-pancreatic islet cells. Cell. 1988; 55(2):281-290

56. Magnan C, et al. Lipid infusion lowers sympathetic nervous activity and leads to increased $\beta$-cell responsiveness to glucose. J Clin Invest. 1999; 103(3):413-419.

57. Wang R, Cruciani-Guglielmacci C, Migrenne S, Magnan C, Cotero VE, Routh VH. Effects of oleic acid on distinct populations of neurons in the hypothalamic arcuate nucleus are dependent on extracellular glucose levels. J Neurophysiol. 2006; 95(3):1491-1498 